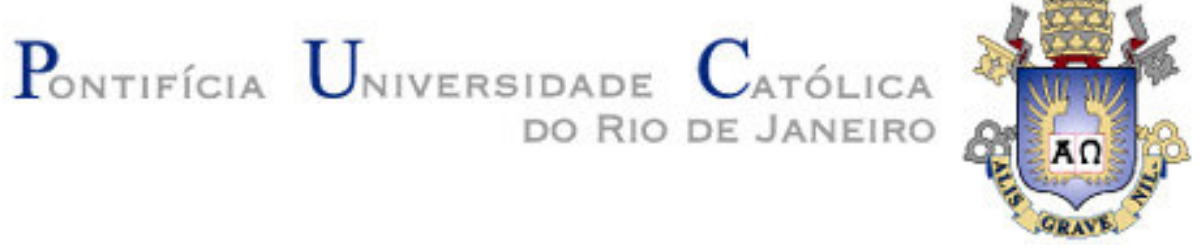

Vanessa Maria De Sousa Maia

\title{
AMORES POSSÍVEIS: um estudo sobre a conjugalidade na Rocinha, Rio de Janeiro
}

Orientadora: Junia de Vilhena

Dissertação apresentada ao Departamento de Psicologia da PUC-Rio como parte dos requisitos para obtenção do título de Mestre em Psicologia. Aprovada pela comissão examinadora abaixo assinada.

Rio de Janeiro

Fevereiro de 2008 
Amores Possíveis: um estudo sobre a conjugalidade na Rocinha, Rio de Janeiro

Dissertação apresentada como requisito parcial para obtenção do grau de Mestre pelo Programa de Pós-Graduação em Psicologia Clínica do Departamento de Psicologia do Centro de Teologia e Ciências Humanas da PUC-Rio. Aprovada pela Comissão Examinadora abaixo assinada.

Profá. Junia de Vilhena

Orientadora

Departamento de Psicologia - PUC-Rio

Prof - Maria Helena Rodrigues Navas Zamora

Departamento de Psicologia - PUC-Rio

Profa. . Anna Paula Uziel Instituto de Psicologia - UERJ

Prof. Paulo Fernando Carneiro de Andrade Coordenador Setorial de Pós-Graduação

e Pesquisa do Centro de Teologia e Ciências Humanas - PUC-Rio

Rio de Janeiro, 
Todos os direitos reservados. É proibida a reprodução total ou parcial do trabalho sem autorização da universidade, do autor e do orientador.

Vanessa Maria de Sousa Maia

Graduou-se em Psicologia pela Pontifícia Universidade Católica do Rio de Janeiro em 2005. Desde 2003 vem exercendo clínica infantil e vincular no contexto comunitário. Realizou pesquisas no campo da psicologia social. Em 2008 iniciou atuação na área de Saúde Mental, no Centro de Atenção Psicossocial Pedra Bonita.

Ficha Catalográfica

Maia, Vanessa Maria de Sousa

Amores possíveis: um estudo sobre a conjugalidade na Rocinha, Rio de Janeiro / Vanessa Maria de Sousa Maia ; orientadora: Junia de Vilhena. - 2008.

$157 \mathrm{f.} ; 30 \mathrm{~cm}$

Dissertação (Mestrado em Psicologia)-Pontifícia Universidade Católica do Rio de Janeiro, Rio de Janeiro, 2008.

Inclui bibliografia

1. Psicologia - Teses. 2. Casamento. 3. Conjugalidade. 4. Amor romântico. 5. Favela. 6. Pobreza. I. Vilhena, Junia. II. Pontifícia Universidade Católica do Rio de Janeiro. Departamento de Psicologia. III. Título. 


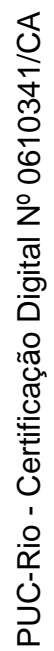

Para meus pais. 


\section{Agradecimentos}

À Junia de Vilhena, minha orientadora, pelo carinho, incentivo, e pela confiança em mim depositada antes mesmo de tudo começar. Sua orientação atenciosa e estimulante tornou o trabalho mais fácil e prazeroso.

Ao Professor Bernardo Jablonski, pela torcida para que este projeto se realizasse.

À Professora Maria Inés Tozatto, por tudo o que, afetuosamente, me ensinou durante os anos em que fui sua estagiária, o que foi fundamental para esta realização.

À Professora Maria Helena Zamora, pelo que pude absorver de suas preciosas aulas, material sempre útil em meu percurso profissional, e também pelas dicas bibliográficas.

Às amigas e companheiras de mestrado Suzana, Cristina, Cecília, Ana Maria, Priscila e Sônia, por nossos encontros revigorantes, e pelo apoio nos momentos mais críticos.

A Sandra Rodrigues, pela presença amiga em todas as horas, e pela grande ajuda prestada neste trabalho.

A Tatiana Cordeiro, pela amizade acolhedora durante todo este percurso.

A Flávio Sérgio, meu maior incentivador, por estar ao meu lado em todos os momentos ofertando sua ajuda incondicional.

Aos meus pais, por tudo o que fizeram por mim para que eu chegasse até aqui.

Aos funcionários do Departamento de Psicologia da PUC-Rio, sempre pacientes e atenciosos em atender às nossas demandas.

A todos os amigos e familiares que, direta ou indiretamente, apoiaram e incentivaram este trabalho.

À CAPES, pelo apoio financeiro concedido durante esses dois anos.

Aos entrevistados, pela disponibilidade e generosidade, sem os quais este trabalho não teria sido possível. 


\section{Resumo}

Maia, Vanessa Maria de Sousa; Vilhena, Junia de. Amores Possíveis: Um estudo sobre a conjugalidade na Rocinha, Rio de Janeiro. Rio de Janeiro, 2008. 157p. Dissertação de Mestrado - Departamento de Psicologia, Pontifícia Universidade Católica do Rio de Janeiro.

Este trabalho tem como objetivo analisar a maneira como se configuram as relações amorosas em uma comunidade da zona sul da cidade do Rio de Janeiro, a Rocinha. Partindo de uma análise do amor romântico e da contextualização da pobreza, buscamos investigar quais os arranjos conjugais possíveis e desejados, dadas as especificidades das condições de vida nessa camada social. Mostramos que a íntima relação entre amor e casamento, tal qual conhecemos hoje, é relativamente recente, e responsável por trazer grande carga de expectativas para os relacionamentos. Análises históricas sobre a família e o casamento nas camadas pobres da população evidenciam uma dinâmica de resistência aos padrões institucionalizados, o que contribuía para sua marginalização. Ainda hoje, são poucos os estudos que abordam este segmento. Dentre eles, alguns atestam que a família pobre estaria mais sujeita a rupturas durante o seu ciclo de desenvolvimento do que a família de classe média ou alta. Assim, a presença, nesta população, de uma representação familiar calcada em ideais românticos apontaria para a existência de conflitos. No entanto, através de uma pesquisa de caráter qualitativo e exploratório, com base em entrevistas semi-estruturadas, percebemos entre os moradores da Rocinha uma enorme capacidade de adequação e adaptação dos valores absorvidos da cultura dominante à sua realidade. A conjugalidade na favela consegue articular valores tradicionais e modernos de maneira conveniente, equilibrando as fortes influências impingidas pelas classes dominantes e pelos veículos de comunicação com as suas reais condições e necessidades. Esses casais produzem, portanto, um modo próprio de conceber as suas relações amorosas.

\section{Palavras-chave}

Casamento; Conjugalidade; Amor romântico; Favela; Pobreza. 


\section{Abstract}

Maia, Vanessa Maria de Sousa; Vilhena, Junia de (Advisor). Possible loves: A study about marital life in Rocinha, Rio de Janeiro. Rio de Janeiro, 2008. 157p. MSc. Dissertation - Departamento de Psicologia, Pontifícia Universidade Católica do Rio de Janeiro.

This research aims to examine the way as amorous relationships are configured in a south area community of Rio de Janeiro city, Rocinha. Starting with an analysis of romantic love and the context of poverty, we search to investigate the conjugal arrangements possible and desirable, given the specific conditions of social life in that layer. We show the close relationship between love and marriage, as it is known today, it is relatively recent, and responsible for bringing large load of relationships expectations. Historical analysis about the family and marriage in poor layers of the population show a resistance to institutionalized patterns, which contributed to their marginalization. Even today, few studies refer to this segment. Among them, some testify that the poor family would be more inclined to disruption during its development cycle, than a family from middle class or high. Thus, the presence, in this population, of a family representation based on romantic ideals would indicate the existence of conflicts. However, through a research of a qualitative and exploratory character, based on semi-structured interviews, it is noticed among residents of Rocinha an enormous capacity for adaptation and values adjustment of the dominant culture absorbed in its reality. The marital life in the slum can articulate traditional and modern values in a convenient way, balancing the strong influences imposed by dominant classes and the vehicles of communication with their actual conditions and needs. These couples produce, therefore, a proper way of designing their own love relationships.

\section{Keywords}

Marriage; Marital life; Romantic love; Slum; Poverty. 


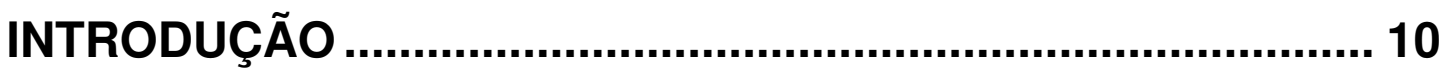

\section{2 - O CASAMENTO ACABOU? A CRISE DO CASAMENTO E}

A FAMÍLIA CONTEMPORÂNEA .............................................. 16

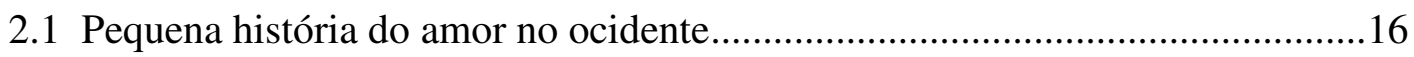

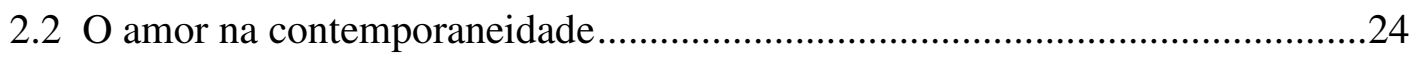

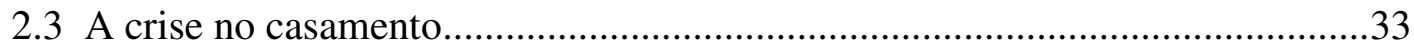

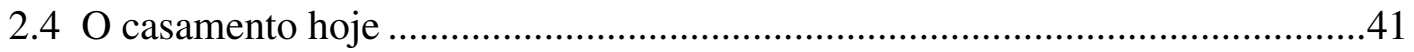

3. ENTRE BECOS E VIELAS - UM OUTRO OLHAR................. 52

$3.1 \mathrm{O}$ desenvolvimento de uma nova pobreza no Brasil ...........................................52

3.1.1 Pobreza e desigualdade .....................................................................52

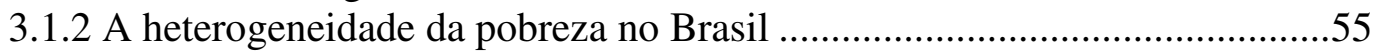

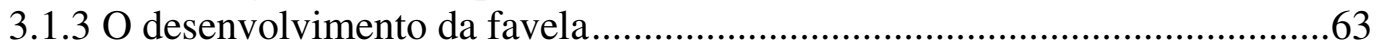

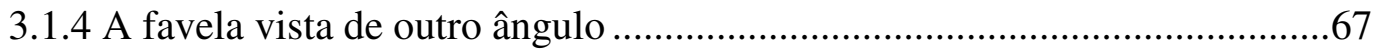

3.2 Família e casamento nas camadas pobres da população ..................................69

3.2.1 A família pobre nas abordagens históricas ..............................................69

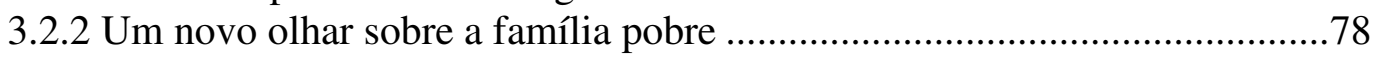

3.2.3 A família pobre urbana na atualidade ...................................................82

\section{JUNTANDO OS “TRAPOS” - SOBRE A CONJUGALIDADE}

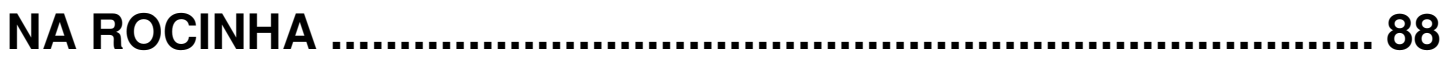

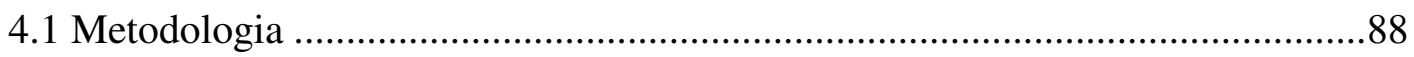

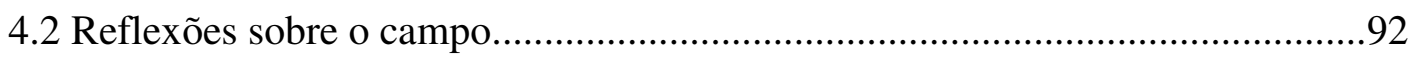

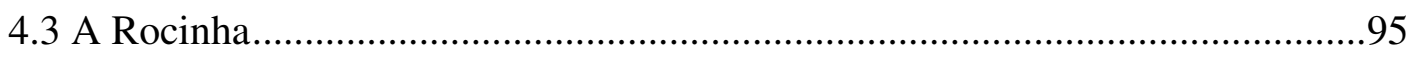

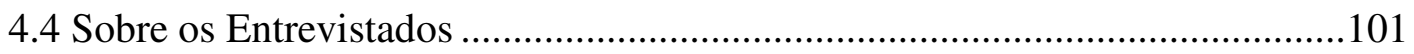

4.5 Nem príncipes, nem sapos - Quando o amor vem depois ................................104

5. CONSIDERAÇÕES FINAIS ............................................ 145

REFERÊNCIAS BIBLIOGRÁFICAS ..................................... 152 
"Lá no morro quando eu olho pra baixo Acho a cidade uma beleza E quando estou na cidade que eu olho pra cima

Fico contemplando a natureza Lá no meu barracão

Quando chove é uma agonia Carrego o colchão e coloco a bacia A nega reclama mas ela me ama Pois sabe que eu sou seu melhor companheiro E assim vou vivendo alegre e contente..." 